Check for updates

Cite this: RSC Adv., 2018, 8, 14640

\title{
Dinuclear molecular magnets with unblocked magnetic connectivity: magnetocaloric effect $\dagger$
}

\author{
Magdalena Fitta, (D) *a Robert Pełka, ${ }^{a}$ Wojciech Sas, ${ }^{\text {ab }}$ Dawid Pinkowicz (D) ${ }^{c}$ \\ and Barbara Siekluckac
}

A detailed study of the magnetocaloric effect in two isostructural bimetallic compounds $\left\{\left[M^{\prime \prime}\left(\mathrm{H}_{2} \mathrm{O}\right)_{2}\right]_{2}\left[\mathrm{Nb}^{\mathrm{IV}}(\mathrm{CN})_{8}\right] \cdot 4 \mathrm{H}_{2} \mathrm{O}\right\}_{n}(\mathrm{M}=\mathrm{Mn}$, Fe) is presented. The substances show sharp phase transitions to the long-range magnetically ordered state with ferromagnetic coupling between $\mathrm{M}$ and $\mathrm{Nb}$ sublattices in the case of the Fe-based sample (FeNb, $T_{c}=43 \mathrm{~K}$ ) and antiferromagnetic coupling for the Mn-based sample $\left(\mathrm{MnNb}, T_{\mathrm{c}}=50 \mathrm{~K}\right)$. The magnetic entropy change was found to reach $5.07 \mathrm{~J} \mathrm{~mol} \mathrm{~K}^{-1} \mathrm{~K}^{-1}(9.09 \mathrm{~J}$ $\mathrm{kg}^{-1} \mathrm{~K}^{-1}$ ) for $\mathrm{MnNb}$ and $4.82 \mathrm{~J} \mathrm{~mol}^{-1} \mathrm{~K}^{-1}\left(8.65 \mathrm{~J} \mathrm{~kg}^{-1} \mathrm{~K}^{-1}\right.$ ) for FeNb under the applied magnetic field change of $5 \mathrm{~T}$. Isothermal entropy changes corresponding to different field changes are demonstrated to collapse on a single master curve, which confirms the magnetic transitions in FeNb and $\mathrm{MnNb}$ to be of the second order. The results obtained for FeNb and $\mathrm{MnNb}$ are discussed in the context of MCE tunability by un/blocking of magnetic connectivity through dis/reconnection of spatially extended ligands.

Received 23rd February 2018 Accepted 12th April 2018

DOI: 10.1039/c8ra01609g

rsc.li/rsc-advances important from the fundamental point of view, as its dependence on temperature and magnetic field change represents the unique characteristic of a material correlated with its critical behaviour.

The first studies of MCE driven by the transition to the longrange magnetically ordered phase dealt with Prussian blue analogues. ${ }^{\mathbf{1 6 - 1 8}}$ Recently, we have presented several examples of the MCE studies for the compounds based on octacyanidometalates, where a special attention was paid to the family of ferrimagnets $\mathrm{Mn}_{2}-\mathrm{L}-\left[\mathrm{Nb}(\mathrm{CN})_{8}\right]$ ( $\mathrm{L}=$ ligand: pyrazole, pyridazine, imidazole). ${ }^{19-21}$ Depending on the bridging ligand or the influence of external stimuli such as external pressure or hydration/dehydration process, these compounds show ordering temperatures within the broad $T_{\mathrm{c}}$ range: $24-98 \mathrm{~K}$. Comparing the maximum entropy change $|\Delta S|^{\max }$ against the ordering temperature for this compound series we proved its $T_{\mathrm{c}}{ }^{-2 / 3}$ dependence. Because MCE is an intrinsic thermodynamic property, its magnitude and dependence on the magnetic field should be related to other magnetic characteristics of the material. In ref. 22 the MCE data were used to investigate the critical behaviour of ferro- and ferrimagnetic molecular materials.

Herein, we report a successive study of MCE in two isostructural bimetallic compounds $\left\{\left[\mathrm{M}^{\mathrm{II}}\left(\mathrm{H}_{2} \mathrm{O}\right)_{2}\right]_{2}\left[\mathrm{Nb}^{\mathrm{IV}}(\mathrm{CN})_{8}\right]\right.$. $\left.4 \mathrm{H}_{2} \mathrm{O}\right\}_{n}(\mathrm{M}=\mathrm{Mn}, \mathrm{Fe})$. The trials to synthesize their analogues with $\mathrm{M}=\mathrm{Co}$ and $\mathrm{Ni}$ were all unsuccessful resulting repeatedly in samples unstable under ambient conditions. $\left\{\left[\mathrm{Mn}^{\mathrm{II}}-\right.\right.$ $\left.\left.\left(\mathrm{H}_{2} \mathrm{O}\right)_{2}\right]_{2}\left[\mathrm{Nb}^{\mathrm{IV}}(\mathrm{CN})_{8}\right] \cdot 4 \mathrm{H}_{2} \mathrm{O}\right\}_{n} \quad(\mathbf{M n N b})$ and $\left\{\left[\mathrm{Fe}^{\mathrm{II}}\left(\mathrm{H}_{2} \mathrm{O}\right)_{2}\right]_{2}[-\right.$ $\left.\left.\mathrm{Nb}^{\mathrm{IV}}(\mathrm{CN})_{8}\right] \cdot 4 \mathrm{H}_{2} \mathrm{O}\right\}_{n}$ (FeNb) crystallize in the same tetragonal space group $I 4 / \mathrm{m}$. In both compounds, octacyanoniobate(Iv) anions are connected via $\mathrm{CN}^{-}$ligands with the $\mathrm{M}^{\mathrm{II}}$ cations,
${ }^{a}$ Institute of Nuclear Physics Polish Academy of Sciences, 31-342 Kraków, Poland ${ }^{b}$ AGH University of Science and Technology, Faculty of Physics and Applied Computer Science, Department of Solid State Physics, al. A. Mickiewicza 30, Krakow 30-059, Poland

${ }^{c}$ Faculty of Chemistry, Jagiellonian University, 30-060 Kraków, Poland. E-mail: Magdalena.Fitta@ifj.edu.pl

$\dagger$ Electronic supplementary information (ESI) available. See DOI: 10.1039/c8ra01609g 
forming a 3D coordination framework (Fig. 1). Each $\mathrm{Nb}$ centre is connected to four $\mathrm{M}^{\mathrm{II}}$ and each $\mathrm{M}^{\mathrm{II}}$ is connected to four $\mathrm{Nb}$ centres. Despite the same structure these compounds show different magnetic properties. FeNb is a soft ferromagnet with $T_{\mathrm{c}}=43 \mathrm{~K}$, while the Mn-based compound orders ferrimagnetically below $50 \mathrm{~K}$.

\section{Experimental details}

Synthesis of $\left\{\left[\mathrm{M}^{\mathrm{II}}\left(\mathrm{H}_{2} \mathrm{O}\right)_{2}\right]_{2}\left[\mathrm{Nb}^{\mathrm{IV}}(\mathrm{CN})_{8}\right] \cdot 4 \mathrm{H}_{2} \mathrm{O}\right\}_{n}(\mathrm{M}=\mathrm{Mn}, \mathrm{Fe})$ and the structural data have been already reported elsewhere. ${ }^{23,24}$ Magnetic measurements were carried out with the MPMS magnetometer. Isothermal magnetization curves recorded up to $5 \mathrm{~T}$ were measured at temperatures ranging from $30 \mathrm{~K}$ up to $65 \mathrm{~K}$.

\section{Results and discussion}

\section{Magnetic properties}

The temperature dependence of the real component of the AC susceptibility $\chi_{\mathrm{ac}}(T)$ of $\mathbf{M n N b}$ and $\mathbf{F e N b}$ was measured with the frequency of $125 \mathrm{~Hz}$ and the amplitude of the oscillating field was equal to 3 Oe. For both compounds $\chi_{\mathrm{ac}}(T)$ shows sharp peaks upon cooling, which indicates the transition to the longrange ordered state. The critical temperatures determined from the minimum of the $\mathrm{d}^{\prime} \chi_{\mathrm{ac}} / \mathrm{d} T$ derivative are $T_{\mathrm{c}}=43 \mathrm{~K}$ and $50 \mathrm{~K}$ for FeNb and MnNb respectively Fig. 2(a).

The magnetization measured for $\mathbf{M n N b}$ at $T=2 \mathrm{~K}$ increases rapidly and reaches the saturation value of $9 \mu_{\mathrm{B}}$ at $5 \mathrm{~T}$. The expected value of magnetization of saturation for the compound with two $\mathrm{Mn}^{\mathrm{II}}$ ions $(S=5 / 2, g=2)$ and one $\mathrm{Nb}^{\mathrm{IV}}$ ion $(S=1 / 2, g=2)$ coupled antiferromagnetically is $9 \mu_{\mathrm{B}}$. This confirms that $\mathbf{M n N b}$ is

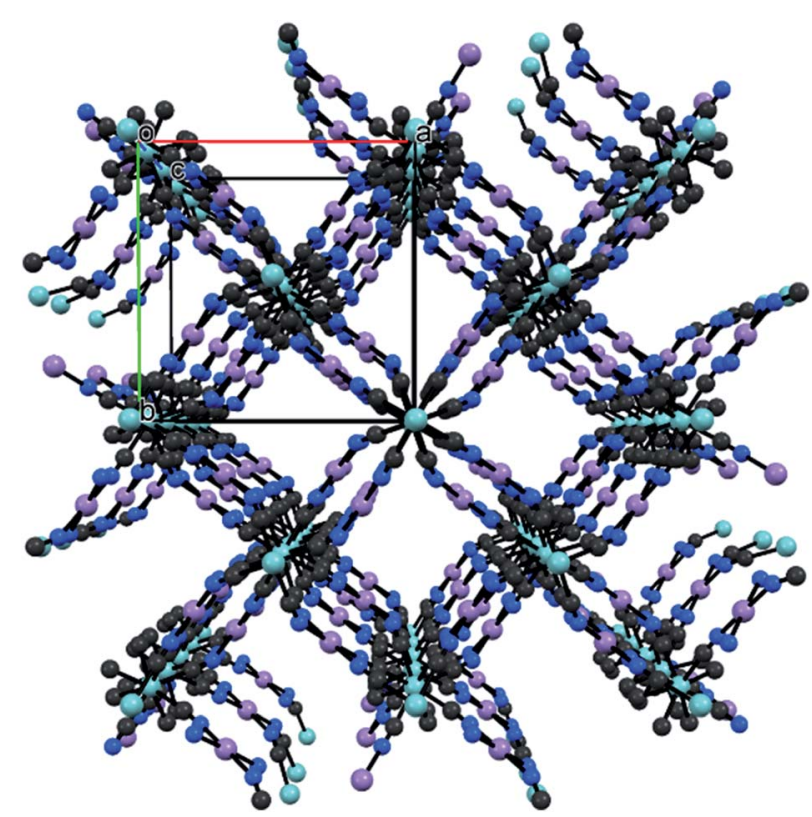

Fig. 1 Three-dimensional $N b^{I V}-C N-M^{\prime \prime}$ coordination framework topology of $\mathrm{MnNb}$ and FeNb. $\mathrm{Nb}^{\mathrm{IV}}$ - cyan, $\mathrm{M}^{\mathrm{II}}$ - pink, $\mathrm{C}$ - black, $\mathrm{N}$ blue. $\mathrm{O}$ and $\mathrm{H}$ atoms are omitted for the sake of clarity. a ferrimagnet with the magnetic moment of the $\mathrm{Nb}$ ion oriented antiparallel to the moments of the two Mn ions.

In the case of the FeNb sample the magnetization does dot saturate attaining the value of $8.5 \mu_{\mathrm{B}}$ at $5 \mathrm{~T}$. The estimated value of magnetization at saturation $\left(=9.46 \mu_{\mathrm{B}}\right)$ was calculated from the limit of the $M=f\left(H^{-1}\right)$ function as $H^{-1}$ tends to zero (see Fig. S5 $\dagger$ ). The expected value of $M_{\text {sat }}$ for two $\mathrm{Fe}^{\mathrm{II}}$ ions $(S=2, g=2.2)$ and one $\mathrm{Nb}^{\mathrm{IV}}$ ion $(S=1 / 2, g=2)$ coupled ferromagnetically is $9.8 \mu_{\mathrm{B}}$, which corroborates the ferromagnetic character of the $\mathrm{Nb}^{\mathrm{IV}}-\mathrm{Fe}^{\mathrm{II}}$ coupling. The hysteresis loop is observed only for FeNb with coercive field $H_{\mathrm{C}}=145$ Oe (Fig. 2(b))

\section{Magnetocaloric effect}

To evaluate the magnetocaloric effect (MCE) of a magnetic material displaying the second-order phase transition the isothermal magnetic entropy change $\left(\Delta S_{M}\right)$ can reliably be calculated via the Maxwell relation:

$$
\begin{aligned}
\Delta S_{M}(T, \Delta H & \left.=H_{2}-H_{1}\right)=S_{M}\left(T, H_{2}\right)-S_{M}\left(T, H_{1}\right) \\
& =\int_{H_{1}}^{H_{2}}\left(\frac{\partial M}{\partial T}\right) \mathrm{d} H
\end{aligned}
$$

where $M$ is the magnetization, $H$ is the magnetic field, and $T$ is the temperature. Fig. $3 \mathrm{a}$ and b show the $M-H$ data of $\mathbf{M n N b}$ and
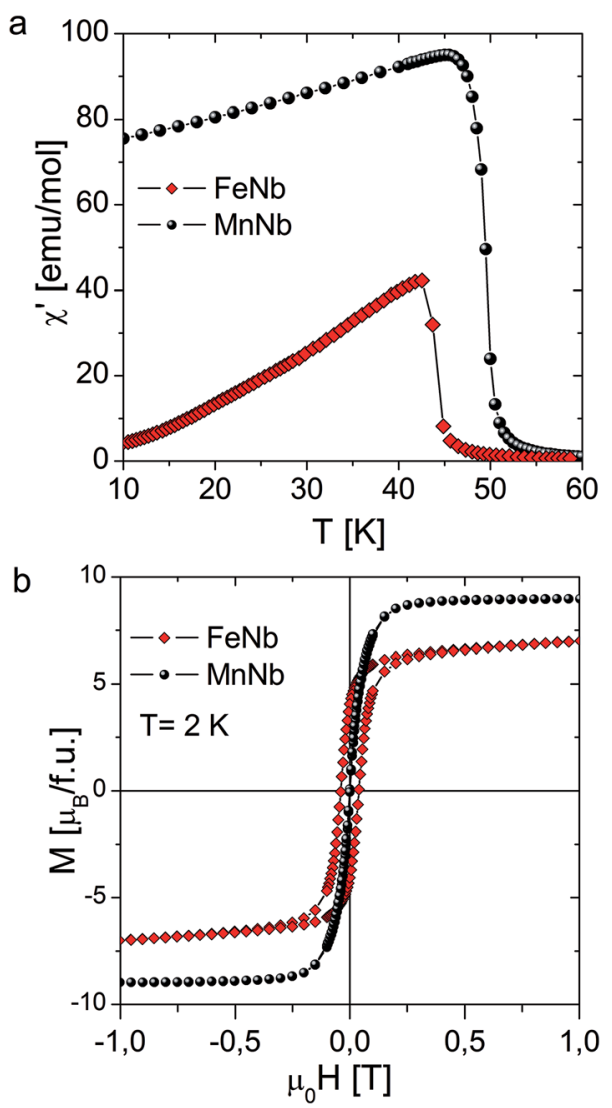

Fig. 2 (a) Temperature dependence of the in-phase ac susceptibility for FeNb and $\mathrm{MnNb}$. (b) Magnetization vs. field measured at $2 \mathrm{~K}$ for $\mathrm{FeNb}$ and $\mathrm{MnNb}$. 

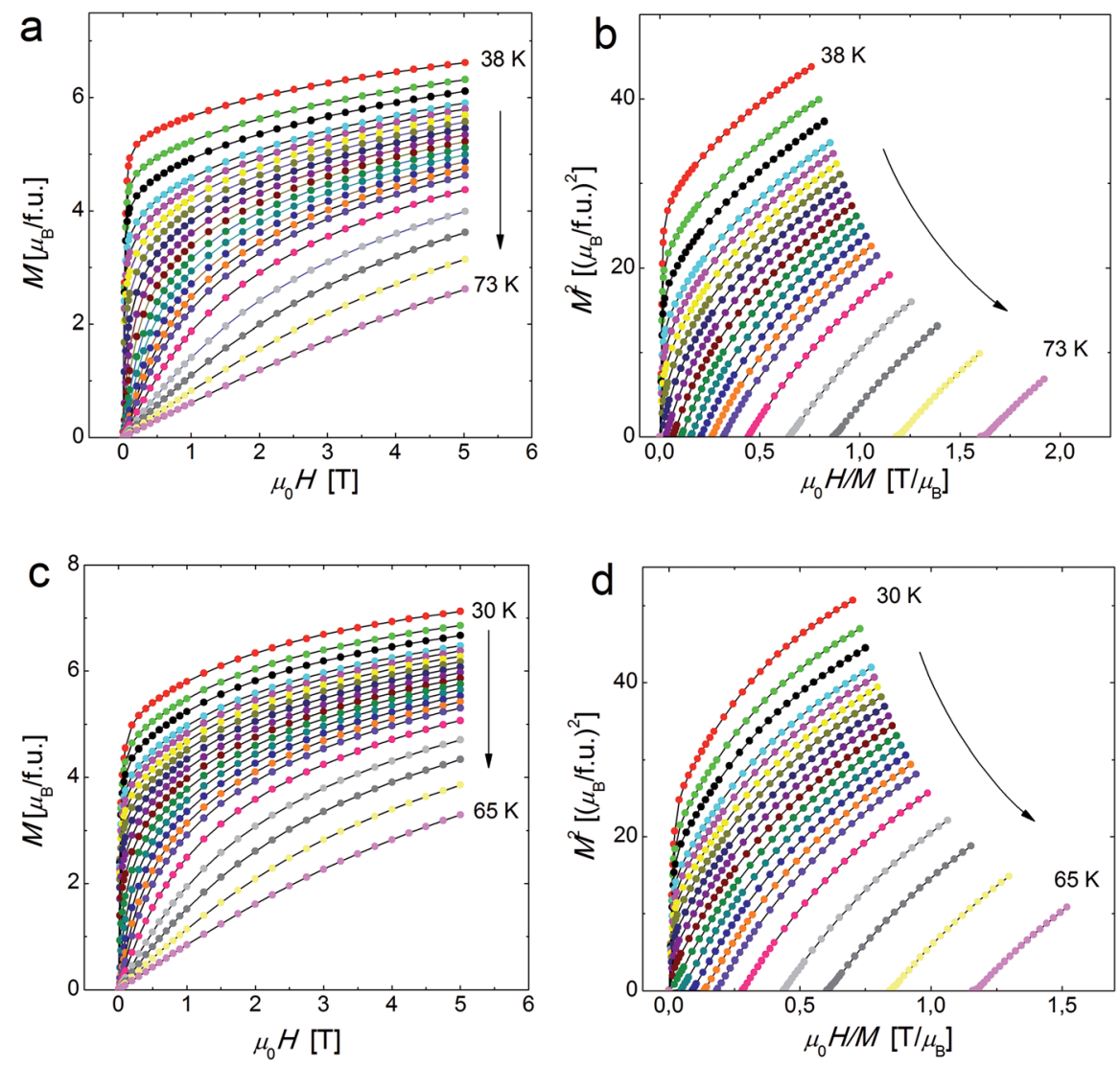

Fig. 3 Magnetization versus field isotherm measured at temperatures in the vicinity of $T_{c}$ for $M n N b(a)$ and FeNb (c). The Arrott plots ( $M^{2}$ vs. $H / M$ ) at the vicinity of $T_{\mathrm{c}}$ for $\mathrm{MnNb}$ (b) and FeNb (d).

FeNb compounds collected at different temperatures for evaluating MCE.

The temperature dependence of $|\Delta S|$ for magnetic field change from 0.5 to $5 \mathrm{~T}$ are presented in Fig. $4 \mathrm{a}$ and b. It can be observed that the magnitude of $\Delta S$ increases with an increase in the applied magnetic field and the magnetic entropy change reaches maximal value near $T_{\mathrm{c}}: 45 \mathrm{~K}$ for $\mathbf{F e N b}$ and $50 \mathrm{~K}$ for MnNb. The maximum values of $|\Delta S|$ are found to be $4.82 \mathrm{~J}$ $\mathrm{mol}^{-1} \mathrm{~K}^{-1}\left(8.65 \mathrm{~J} \mathrm{~kg}^{-1} \mathrm{~K}^{-1}\right)$ and $5.07 \mathrm{~J} \mathrm{~mol}^{-1} \mathrm{~K}^{-1}\left(9.09 \mathrm{~J} \mathrm{~kg}^{-1}\right.$ $\mathrm{K}^{-1}$ ) for the field change of $0-5 \mathrm{~T}$ for $\mathbf{F e N b}$ and $\mathbf{M n N b}$, respectively.

The magnitude of magnetocaloric effect in a magnetic system depends on type of magnetic interaction, presence of magnetic anisotropy, magnetic density and constituent spin values. Therefore, through the control of these parameters in a given structure one can tune the magnitude of magnetic entropy change. The replacement of $\mathrm{Fe}$ by $\mathrm{Mn}$ in the $\left\{\left[\mathrm{M}^{\mathrm{II}}\left(\mathrm{H}_{2} \mathrm{O}\right)_{2}\right]_{2}\left[\mathrm{Nb}^{\mathrm{IV}}(\mathrm{CN})_{8}\right] \cdot 4 \mathrm{H}_{2} \mathrm{O}\right\}_{n}$ structure brings about the increase in $|\Delta S|^{\max }$ as well as in the temperature where the maximum value of the entropy change occurs. Slightly higher values of $|\Delta S|^{\max }$ observed for $\mathbf{M n N b}$ is may be related to the spin value of the $\mathrm{Mn}^{\mathrm{II}}$ ion $\left(S_{\mathrm{Mn}}=5 / 2\right)$ being higher than that of the $\mathrm{Fe}^{\mathrm{II}}$ ion $\left(S_{\mathrm{Fe}}=2\right)$. Besides, the $\mathrm{Mn}^{\mathrm{II}}$ ion is devoid of any intrinsic magnetic anisotropy, which corresponds to the halffull filling of the $3 \mathrm{~d}$ orbital $\left(3 \mathrm{~d}^{5}\right.$ electronic configuration) preventing any orbital contribution in its ground state. At the same time, the orbital contribution may not be fully quenched by the crystal field in the case of the $\mathrm{Fe}^{\mathrm{II}}$ ion $\left(3 \mathrm{~d}^{6}\right.$ electronic configuration) leading to a material magnetocrystalline anisotropy.

Much larger differences in the values of $|\Delta S|^{\max }$ were observed for the isostructural series of $\left\{\left[\mathrm{M}^{\mathrm{II}}(\text { pyrazole })_{4}\right]_{2^{-}}\right.$ $\left.\left[\mathrm{Nb}^{\mathrm{IV}}(\mathrm{CN})_{8}\right] \cdot 4 \mathrm{H}_{2} \mathrm{O}\right\}_{n}$, where $\mathrm{M}=\mathrm{Mn}, \mathrm{Fe}$, and pyrazole is the 5membered $\mathrm{C}_{3} \mathrm{H}_{4} \mathrm{~N}_{2}$ ring ligand. ${ }^{22,26}$ The exchange coupling in both compounds is of antiferromagnetic character triggering off transitions to long-range ferrimagnetically ordered phases at $23.8 \mathrm{~K}$ and $7.8 \mathrm{~K}$ for $\mathrm{M}=\mathrm{Mn}$ and $\mathrm{Fe}$, respectively. In this case the value of $|\Delta S|^{\max }=4.9 \mathrm{~J} \mathrm{~mol}^{-1} \mathrm{~K}^{-1}\left(4.8 \mathrm{~J} \mathrm{~kg}^{-1} \mathrm{~K}^{-1}\right)$ detected for the Fe-based compound is again apparently lower than that observed for the Mn-based sample $6.7 \mathrm{~J} \mathrm{~mol}^{-1} \mathrm{~K}^{-1}\left(6.5 \mathrm{~J} \mathrm{~kg}^{-1}\right.$ $\mathrm{K}^{-1}$ ) Table 1Link as table 1 . The presence of the pyrazole ligand in this family of molecular magnets works as a steric factor blocking the magnetic connectivity of the constituent ions. They crystallize in the tetragonal space group $I 4_{1} / a$ with the structure consisting of a 3D skeleton, where each $\mathrm{Nb}^{\mathrm{TV}}$ center is linked through the cyanido bridges $\mathrm{Nb}^{\mathrm{IV}}-\mathrm{CN}-\mathrm{M}^{\mathrm{II}}$ to four $\mathrm{M}^{\mathrm{II}}$ ions, whereas each $\mathrm{M}^{\mathrm{II}}$ center is bridged to only two $\mathrm{Nb}^{\mathrm{IV}}$ ions. The remaining part of the six-membered coordination sphere of $\mathrm{Fe}^{\mathrm{II}}$ is filled with pyrazole molecules, while the $\mathrm{Nb}^{\mathrm{IV}}$ ion coordinates further four terminal $\mathrm{CN}^{-}$ligands. It is the removal of the pyrazole ligand from the synthetic procedure that leads to the crystallization of the studied compounds with the number of the $\mathrm{M}^{\mathrm{II}}-\mathrm{NC}-\mathrm{Nb}^{\mathrm{IV}}$ linkages twice as large as in the pyrazole 

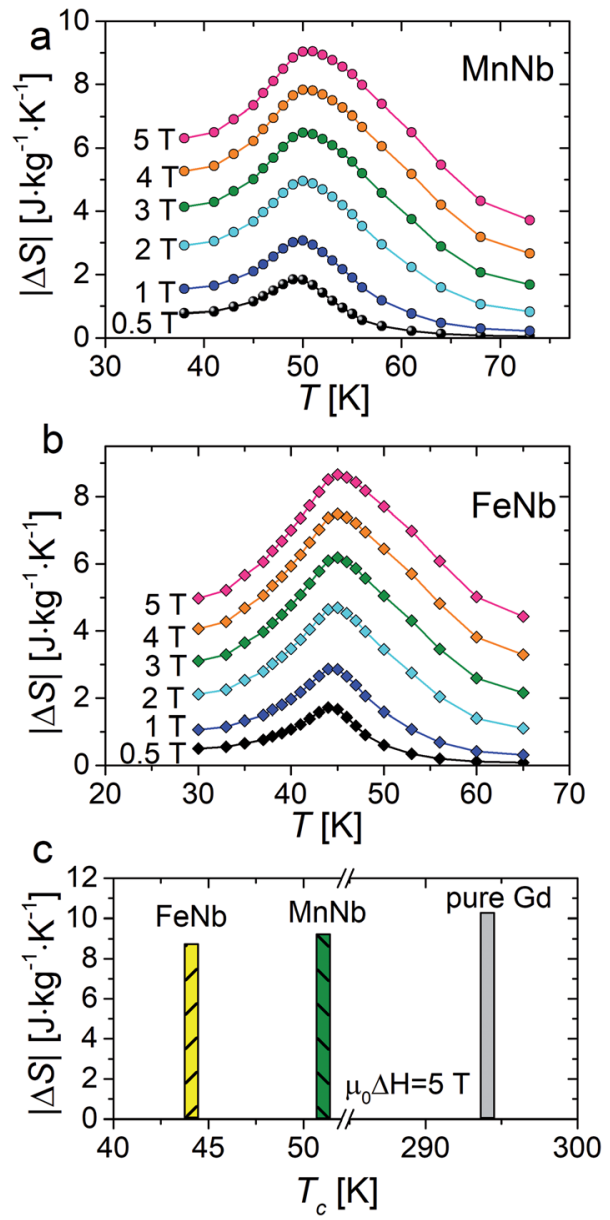

Fig. 4 The temperature dependence of magnetic entropy change recorded in various magnetic fields $(0.5-5 \mathrm{~T}$ ) for $\mathrm{MnNb}$ (a) and $\mathrm{FeNb}$ (b). Comparative histograms of $|\Delta S|$ values obtained for FeNb, $\mathrm{MnNb}$ and pure gadolinium ${ }^{25}$ in the applied field of $5 \mathrm{~T}$ (c).

containing analogues. This substantial enhancement of magnetic connectivity gives rise to two effects. Firstly, the transition points of the studied samples are considerably shifted toward higher temperatures (by 25-35 K). Secondly, the magnitude of MCE $\left(\Delta S\right.$ in $\left.\mathrm{kg}^{-1} \mathrm{~K}^{-1}\right)$ of the pyrazole-free compounds is significantly higher than that of their pyrazole containing counterparts, which is related to the increased magnetic density of the compounds with unblocked magnetic connectivity, see Fig. 5. Let us note that at the same time the molar MCE quantities $(\Delta S$ in J $\mathrm{mol}^{-1} \mathrm{~K}^{-1}$ ) display the reverse order with smaller differences: $5.07 \mathrm{~J} \mathrm{~mol}^{-1} \mathrm{~K}^{-1}$ against $6.7 \mathrm{~J} \mathrm{~mol}^{-1} \mathrm{~K}^{-1}$ for the Mn-based compounds, and $4.82 \mathrm{~J} \mathrm{~mol}^{-1} \mathrm{~K}^{-1}$ against $4.9 \mathrm{~J} \mathrm{~mol}^{-1} \mathrm{~K}^{-1}$ for the Fe-based compounds. This can be understood by remembering that for the same number of $\mathrm{M}_{2} \mathrm{Nb}(\mathrm{M}=\mathrm{Mn}, \mathrm{Fe})$ units the magnitude of $\Delta S$ is expected to be attenuated with increasing temperature.

The value of $|\Delta S|^{\text {max }}$ determined for $\mathbf{M n N b}$ matches quite well the trend displayed by the recently published results of MCE obtained for the ligand-tuned ferrimagnetic $\mathrm{Mn}_{2}-\mathrm{L}-\left[\mathrm{Nb}(\mathrm{CN})_{8}\right](\mathrm{L}$ $=$ ligand) networks. Depending on the bridging ligand as well as external stimuli such as dehydration or external pressure, the critical temperature of the compound changes from $24 \mathrm{~K}$ to $98 \mathrm{~K}$.

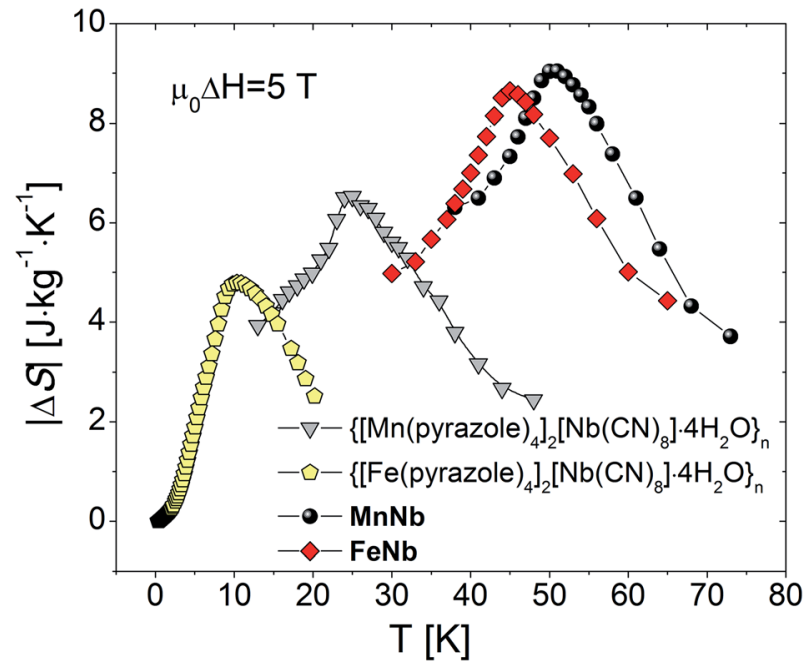

Fig. 5 Magnetic entropy change of $\mathrm{MnNb}, \mathrm{FeNb}$ and $\left\{\left[\mathrm{M}^{\prime \prime}(\text { pyrazole })_{4}\right]_{2}\left[\mathrm{Nb}^{\mathrm{IV}}(\mathrm{CN})_{8}\right] \cdot 4 \mathrm{H}_{2} \mathrm{O}\right\}_{n}(\mathrm{M}=\mathrm{Mn}$, Fe) determined for magnetic field change from 0 to $5 \mathrm{~T}$.

As it was predicted by Oesterreicher and Parker for the compounds with the same spin content and different critical temperatures, the decrease in $|\Delta S|^{\max }$ (in $\mathrm{J} \mathrm{mol}^{-1} \mathrm{~K}^{-1}$ ) should be consistent with $|\Delta S|^{\max } \sim T_{\mathrm{c}}{ }^{-2 / 3}$ for increasing $T_{\mathrm{c}}{ }^{27}$ Fig. S6 $\dagger$ shows the comparison of MCE data obtained for MnNb and other
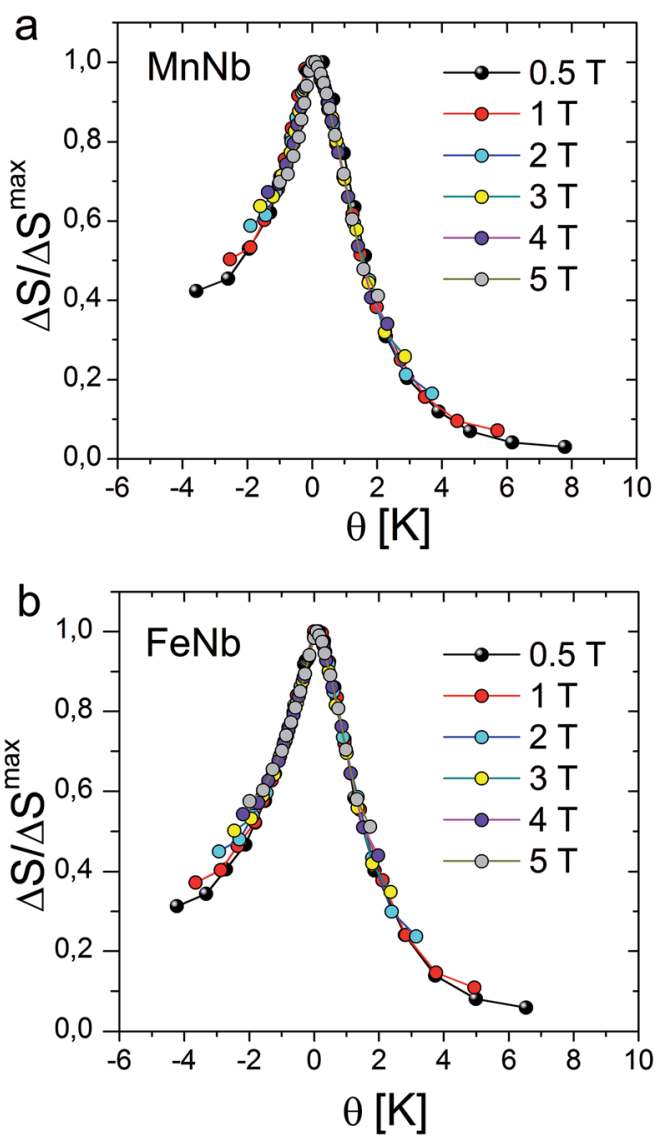

Fig. 6 Universal curves of $\mathrm{MnNb}(\mathrm{a})$ and FeNb (b). 
$\mathrm{Mn}_{2}-\mathrm{L}-\left[\mathrm{Nb}(\mathrm{CN})_{8}\right]$ compounds where $T_{\mathrm{c}}{ }^{-2 / 3}$ dependence of the maximum entropy change has been confirmed for this series.

A useful parameter which quantifies the efficiency of a magnetocaloric material is the relative cooling power (RCP). RCP corresponds to the amount of heat that can be transferred between the cold and hot reservoirs in one ideal thermodynamic cycle. It can be calculated by integrating the $|\Delta S|(T)$ curve over the full width at half maximum:

$$
\mathrm{RCP}=\int_{T_{1}}^{T_{2}} \Delta S \mathrm{~d} T
$$

where $T_{1}, T_{2}$ are the lower and higher temperature at half maximum of the magnetic entropy change and can be considered as the temperatures of the hot and cold reservoirs, respectively. For an applied magnetic field of $5 \mathrm{~T}$, the RCP is equal to 118.40 and $125.43 \mathrm{~J} \mathrm{~mol}^{-1}$ (212.61 and $225.59 \mathrm{~J} \mathrm{~kg}^{-1}$ ) for MnNb and FeNb, respectively. These values of RCP make about $50 \%$ of that of pure gadolinium. ${ }^{25}$

Recently, the universal curve of magnetic entropy change has been developed and successfully applied to determine an order of phase transition in some materials. ${ }^{28,29}$ For materials undergoing the second-order phase transition, $\Delta S(T)$ curves measured with different applied fields were argued to collapse into a single master curve. The phenomenological universal curve can be constructed by normalizing all the $\Delta S(T)$ curves using their maximum value $\Delta S^{\max }$ and, subsequently, re-scaling the temperature axis independently below and above the critical temperature. The new reduced temperature variable $\theta$ is defined by the following expression:

$$
\theta=\frac{-\left(T-T_{\mathrm{c}}\right)}{\left(T_{\mathrm{r} 1}-T_{\mathrm{c}}\right)}, \quad T \leq T_{\mathrm{c}} ; \theta=\frac{\left(T-T_{\mathrm{c}}\right)}{\left(T_{\mathrm{r} 2}-T_{\mathrm{c}}\right)}, \quad T>T_{\mathrm{c}}
$$

where $T_{\mathrm{r} 1}, T_{\mathrm{r} 2}$ are the temperatures of two reference points. Values of $T_{\mathrm{r} 1}, T_{\mathrm{r} 2}$ are determined by numerically solving equation $\Delta S\left(T_{\mathrm{r}}\right) / \Delta S^{\max }=0.7$ below and above $T_{\mathrm{c}}$, respectively, and are listed in Table S1. $\dagger$ The selection of the reference entropy change of 0.7 was made in such a way that the curves to be overlapped have experimental values above that value for temperatures below and above $T_{\mathrm{c}}$.

Let us note, see Fig. 6, that all the rescaled $\Delta S(T)$ curves neatly collapse on one master curve in a wide temperature

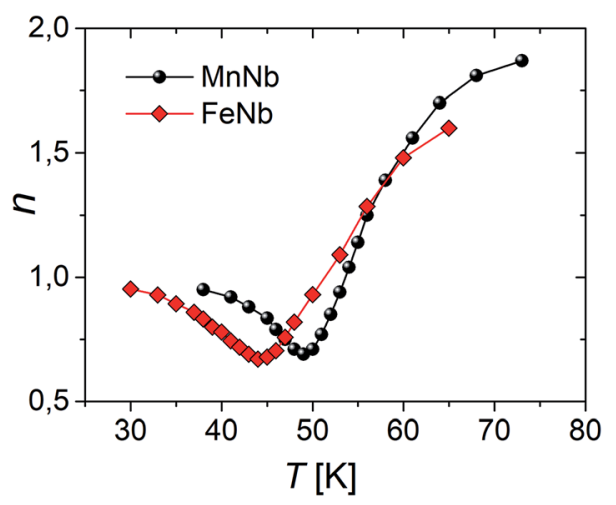

Fig. 7 Temperature dependence of exponent $n$ characterizing the field dependence of $\Delta S$.
Table 1 Comparison MCE data obtained for molecular magnets based on octacyanoniobate and pure gadolinium. $T_{\mathrm{c}}$ determined from $\mathrm{d}^{\prime} \chi / \mathrm{d} T ;|\Delta S|^{\text {max }}$-maximum of magnetic entropy change determined for $\mu_{0} \Delta H=5 \mathrm{~T} ; n_{T_{c}}-$ critical exponent describing field dependence of

\begin{tabular}{|c|c|c|c|c|}
\hline & $T_{\mathrm{c}}(\mathrm{K})$ & $\begin{array}{l}|\Delta S|^{\max } \\
\left(\mathrm{J} \mathrm{kg}^{-1} \mathrm{~K}^{-1}\right)\end{array}$ & $n_{T_{\mathrm{c}}}$ & Ref. \\
\hline FeNb & 43.0 & 8.65 & 0.67 & $\begin{array}{l}\text { This } \\
\text { work }\end{array}$ \\
\hline MnNb & 50.0 & 9.09 & 0.69 & $\begin{array}{l}\text { This } \\
\text { work }\end{array}$ \\
\hline $\begin{array}{l}\left\{\left[\mathrm{Fe}^{\mathrm{II}}(\mathrm{pyr})_{4}\right]_{2}\left[\mathrm{Nb}^{\mathrm{IV}}(\mathrm{CN})_{8}\right] \cdot 4 \mathrm{H}_{2} \mathrm{O}\right\}_{n} \\
\text { pyr }=\text { pyrazole }\end{array}$ & 7.8 & 4.8 & 0.64 & 26 \\
\hline $\begin{array}{l}\left\{\left[\mathrm{Mn}^{\mathrm{II}}(\mathrm{pyr})_{4}\right]_{2}\left[\mathrm{Nb}^{\mathrm{IV}}(\mathrm{CN})_{8}\right] \cdot 4 \mathrm{H}_{2} \mathrm{O}\right\}_{n}, \\
\text { pyr }=\text { pyrazole }\end{array}$ & 23.8 & 6.5 & 0.64 & 22 \\
\hline Gd & 294 & 10.2 & & 25 \\
\hline
\end{tabular}
$\Delta S$ at $T=T_{\mathrm{C}}$

range, corroborating the second order magnetic phase transition in the ferromagnetic FeNb as well as in the ferrimagnetic MnNb. The order of the magnetic phase transition can be also tested by an analysis of the Arrott plots. According to the Banerjee criterion, ${ }^{30}$ a positive slope of the $M^{2}$ versus $H / M$ curves indicates a magnetic phase transition to be of the second order, while a negative slope corresponds to the first order phase transition. The positive slope of the curves presented in Fig. $3 \mathrm{~b}$ and $\mathrm{d}$ is consistent with the universal scaling of the $\Delta S(T)$ curves.

Concerning the magnetic-field dependence of the magnetic entropy changes it has been found that this dependence can be expressed by a power law $|\Delta S|(T, H) \propto H^{n}$ where $n$ is related to the magnetic state of a sample. Fig. 7 shows the temperature dependence of the field-averaged exponent $n$ for the studied compounds estimated on the basis of the data in Fig. $4 \mathrm{a}$ and $\mathrm{b}$. The power law relation, proposed in the literature ${ }^{28}$ for materials with the second order phase transition in general anticipates $n=1$ and $n=2$ for temperatures quite far below and above $T_{\mathrm{c}}$. For both compounds the minimum of $n$ is observed at $T=T_{\mathrm{c}}$ and is equal to 0.67 for FeNb and 0.69 for $\mathbf{M n N b}$.

\section{Summary and conclusion}

In this work, we have carried out the comprehensive study of magnetocaloric effect in two structure related molecular magnets $\left\{\left[\mathrm{M}^{\mathrm{II}}\left(\mathrm{H}_{2} \mathrm{O}\right)_{2}\right]_{2}\left[\mathrm{Nb}^{\mathrm{IV}}(\mathrm{CN})_{8}\right] \cdot 4 \mathrm{H}_{2} \mathrm{O}\right\}_{n}(\mathrm{M}=\mathrm{Mn}, \mathrm{Fe})$, where the Fe-based compound is a soft ferromagnet with $T_{\mathrm{c}}=43 \mathrm{~K}$, while the Mn-based sample orders ferrimagnetically below $T_{\mathrm{c}}=$ $50 \mathrm{~K}$.

The magnetocaloric effect was determined from the measurements of the field dependence of the magnetization at different temperatures. It was demonstrated that the replacement of Fe by $\mathrm{Mn}$ in $\left\{\left[\mathrm{M}^{\mathrm{II}}\left(\mathrm{H}_{2} \mathrm{O}\right)_{2}\right]_{2}\left[\mathrm{Nb}^{\mathrm{IV}}(\mathrm{CN})_{8}\right] \cdot 4 \mathrm{H}_{2} \mathrm{O}\right\}_{n}$ brings about the increase in the $|\Delta S|^{\max }$ value as well as in the temperature where the maximum value of the entropy change occurs. The maximum values of the magnetic entropy change were found to amount to $4.82 \mathrm{~J} \mathrm{~mol}^{-1} \mathrm{~K}^{-1}$ and $5.07 \mathrm{~J} \mathrm{~mol}^{-1} \mathrm{~K}^{-1}$ at $\mu_{0} \Delta H=5 \mathrm{~T}$ for $\mathbf{F e N b}$ and $\mathbf{M n N b}$, respectively. Any significant 
differences were not noticed in the analysis of $\Delta S(T)$ master curves. For both compounds correct universal curves, typical for the magnetic transition of the second order, were obtained. The favourable influence of unblocking the magnetic connectivity on MCE was demonstrated through the comparison of the studied samples to the ligand containing compounds $\left.\left\{\left[\mathrm{M}^{\mathrm{II}} \text { (pyrazole }\right)_{4}\right]_{2}\left[\mathrm{Nb}^{\mathrm{IV}}(\mathrm{CN})_{8}\right] \cdot 4 \mathrm{H}_{2} \mathrm{O}\right\}_{n}$ with $\mathrm{M}=\mathrm{Mn}$, Fe.

In summary, the relatively large values of the magnetocaloric effect and the values of RCP observed in the studied molecular magnets encourage to consider them as efficient refrigerants working in the low temperature regime.

\section{Conflicts of interest}

There are no conflicts to declare.

\section{Acknowledgements}

This work was supported by the Polish National Science Centre within the frame of Project No. UMO-2011/03/D/ST5/05400.

\section{References}

1 J. Romero Gómez, R. Ferreiro Garcia, A. De Miguel Catoira and M. Romero Gómez, Renewable and Sustainable Energy Reviews, 2013, 17, 74.

2 V. K. Pecharsky and K. A. Gschneidner Jr, J. Magn. Magn. Mater., 1999, 200, 44.

3 V. Franco, J. S. Blázquez, B. Ingale and A. Conde, Annu. Rev. Mater. Res., 2012, 42, 305.

4 V. K. Pecharsky and K. A. Gschneidner Jr, Phys. Rev. Lett., 1997, 78, 4494.

5 O. Tegus, E. Bruck, K. H. J. Buschow and F. R. de Boer, Nature, 2002, 415, 150.

6 B. G. Shen, J. R. Sun, F. X. Hu, H. W. Zhang and Z. H. Cheng, Adv. Mater., 2009, 21, 4545.

7 R. Sessoli, Angew. Chem., Int. Ed., 2012, 51, 43.

8 M. Evangelisti and E. K. Brechin, Dalton Trans., 2010, 39, 4672.

9 J. W. Sharples, D. Collison, E. J. L. McInnes, J. Schnack, E. Palacios and M. Evangelisti, Nat. Commun., 2014, 5, 5321.

10 M. Gajewski, R. Pełka, M. Fitta, Y. Miyazaki, Y. Nakazawa, M. Bałanda, M. Reczyński, B. Nowicka and B. Sieklucka, J. Magn. Magn. Mater., 2016, 414, 25.

11 J. P. Zhao, R. Zhao, Q. Yang, B. W. Hu, F. Ch. Liu and X. H. Bu, Dalton Trans., 2013, 42, 14509.

12 G. Lorusso, O. Roubeau and M. Evangelisti, Angew. Chem., Int. Ed., 2016, 55, 3360.
13 P. Konieczny, S. Chorąży, R. Pełka, K. Bednarek, T. Wasiutyński, S. Baran, B. Sieklucka and R. Podgajny, Inorg. Chem., 2017, 56, 7089.

14 P. Konieczny, Ł. Michalski, R. Podgajny, S. Chorąży, R. Pełka, D. Czernia, S. Buda, J. Mlynarski, B. Sieklucka and T. Wasiutyński, Inorg. Chem., 2017, 56, 2777.

15 P. Konieczny, R. Pełka, D. Czernia and R. Podgajny, Inorg. Chem., 2017, 56, 11971.

16 E. Manuel, M. Evangelisti, M. Affronte, M. Okubo, C. Train and M. Verdaguer, Phys. Rev. B: Condens. Matter Mater. Phys., 2006, 73, 172406.

17 M. Evangelisti, E. Manuel, M. Affronte, M. Okubo, C. Train and M. Verdaguer, J. Magn. Magn. Mater., 2007, 316, e569.

18 S. M. Yusuf, A. Kumar and J. V. Yakhmi, Appl. Phys. Lett., 2009, 95, 182506.

19 M. Fitta, R. Pełka, M. Gajewski, M. Mihalik, M. Zentkova, D. Pinkowicz, B. Sieklucka and M. Bałanda, J. Magn. Magn. Mater., 2015, 396, 1.

20 M. Fitta, M. Bałanda, R. Pełka, P. Konieczny, D. Pinkowicz and B. Sieklucka, J. Phys.: Condens. Matter, 2013, 25, 496012.

21 M. Fitta, R. Pełka, M. Bałanda, M. Czapla, M. Mihalik, D. Pinkowicz, B. Sieklucka, T. Wasiutyński and M. Zentkova, Eur. J. Inorg. Chem., 2012, 3830.

22 M. Fitta, M. Bałanda, M. Mihalik, R. Pełka, D. Pinkowicz, B. Sieklucka and M. Zentkova, J. Phys.: Condens. Matter, 2012, 24, 506002.

23 D. Pinkowicz, R. Podgajny, R. Pelka, W. Nitek, M. Balanda, M. Makarewicz, M. Czapla, J. Zukrowski, Cz. Kapusta, D. Zajac and B. Sieklucka, Dalton Trans., 2009, 7771.

24 J. M. Herrera, P. Franz, R. Podgajny, M. Pilkington, M. Biner, S. Decurtins, H. Stoeckli-Evans, A. Neels, R. Garde, Y. Dromźee, M. Julve, B. Sieklucka, K. Hashimoto, S. Okhoshi and M. Verdaguer, C. R. Chim., 2008, 11, 1192.

25 K. A. Gschneidner, V. K. Pecharsky and A. O. Tsokol, Rep. Prog. Phys., 2005, 68, 1479.

26 R. Pełka, P. Konieczny, P. M. Zieliński, T. Wasiutyński, Y. Miyazaki, A. Inaba, D. Pinkowicz and B. Sieklucka, J. Magn. Magn. Mater., 2014, 354, 359.

27 H. Oesterreicher and F. T. Parker, J. Appl. Phys., 1984, 55, 4334.

28 V. Franco, J. S. Bĺazquez and A. Conde, Appl. Phys. Lett., 2006, 89, 222512.

29 V. Franco, A. Conde, J. M. Romero-Enrique and J. S. Bĺazquez, J. Phys.: Condens. Matter, 2008, 20, 285207.

30 S. K. Banerjee, Phys. Lett., 1964, 12, 16. 